\title{
Capítulo V - A educação no contexto da hegemonia, da ideologia e da linguagem
}

\author{
Anita Helena Schlesener
}

\section{SciELO Books / SciELO Livros / SciELO Libros}

SCHLESENER, AH. A educação no contexto da hegemonia, da ideologia e da linguagem. In: Grilhões invisiveis: as dimensões da ideologia, as condições de subalternidade e a educação em Gramsci [online]. Ponta Grossa: Editora UEPG, 2016, pp. 151-177. ISBN 978-85-7798-234-9. Available from: doi: 10.7476/9788577982349.0006. Also available in ePUB from: http://books.scielo.org/id/y3zhj/epub/Schlesener-9788577982349.epub.

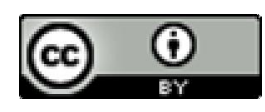

All the contents of this work, except where otherwise noted, is licensed under a Creative Commons Attribution 4.0 International license.

Todo o conteúdo deste trabalho, exceto quando houver ressalva, é publicado sob a licença Creative Commons Atribição 4.0.

Todo el contenido de esta obra, excepto donde se indique lo contrario, está bajo licencia de la licencia Creative Commons Reconocimento 4.0. 


\section{CAPÍTULO \\ A Educação no CONTEXTo da Hegemonia, DA IDEOLOGIA E DA LINGUAGEM}

Ao abordar a questão da educação pretendemos explicitar o significado da leitura de Gramsci ante as grandes transformações políticas e culturais que caracterizam este início do século XXI. Embora seus escritos sejam contextualizados e o capitalismo tenha hoje novas configurações, as contribuições de Gramsci para entender a educação são muito importantes, na medida em que se voltam para redefinir a questão das relações de hegemonia e seus pressupostos ideológicos enquanto consolidam a dominação fundando-a na obediência passiva. A educação perpassa a questão da hegemonia, a formação e superação de ideologias e tem uma importância fundamental na apropriação dos códigos de construção de projetos racionais. Os projetos, assim como as ideologias, se materializam na vida cotidiana por meio da linguagem. Pensar de modo autônomo e expressar claramente as ideias tem grande significado na luta política.

Dessa perspectiva, retomamos alguns aspectos da crítica ao sistema parlamentar no contexto da democracia burguesa, sustentados pela separação formal entre economia e política, esta construída a partir de uma estrutura jurídica que permite dar à ideologia uma dimensão desmesurada nas imagens de participação política e de igualdade dos indivíduos, para explicitar o significado da educação. O contexto da estrutura do Estado serve de base para entender tanto os limites do sistema parlamentar na democracia burguesa quanto os limites das políticas públicas educacionais diante da escassa representatividade que as classes populares alcançam no interior deste sistema.

Em seguida, abordam-se as formas de domínio que se efetivam na educação, ainda entendida no seu sentido amplo, ou seja, como formação dos indivíduos para um determinado modelo de sociedade. Gramsci aborda várias situações em que a educação pode se apresentar como um dos mecanismos de assimilação das relações de poder vigentes e de consolidação da dominação, principalmente por mecanismos ideológicos. Neste contexto, as 
características ideológicas de manuais que garantem a formação no exército, na Igreja e no sistema carcerário italiano.

Retomamos ainda o discurso ideológico conservador e seus desdobramentos no processo educativo das classes subalternas a partir de uma falsa ideia de neutralidade cientifica e de uma verdade universal pretensamente expressa por este ideário. Tem-se que partir de dois pressupostos: 1) a historicidade do pensamento e suas origens práticas, que implicam que a verdade é histórica; 2) a divisão da sociedade em classes sociais antagônicas e a desigualdade social implicam que toda manifestação teórica parte de uma perspectiva de classe. Neste contexto, toda verdade que se acredita eterna e absoluta precisa ser desmistificada, mostrando seu caráter histórico e seu valor provisório.

Finalmente, a partir do entendimento da luta de classes e das novas dimensões que esta assume, cabe abordar a função emancipatória da educação para as classes subalternas, a partir da articulação entre política e educação.

\section{A estrutura parlamentar na democracia burguesa e as políticas públicas educacionais}

Estranhem o que não for estranho. Tomem por inexplicável o habitual. Sintam-se perplexos ante o cotidiano. Tratem de achar um remédio para o abuso, mas não esqueçam de que o abuso é sempre a regra (BRECHT, 1982, p. 15).

Como explicitamos no primeiro capítulo, Gramsci destaca os limites do sistema parlamentar no contexto da democracia burguesa a partir de alguns pressupostos como a formação do senso comum, do individualismo voltado para a apropriação do lucro e da estrutura partidária voltada para o processo eleitoral. A questão de fundo que determina a forma do sistema parlamentar é o modelo de capitalismo que se implanta, ou seja, no caso da Itália, o processo conservador que caracterizou a unificação do Estado tendeu a deixar à margem os trabalhadores em geral, principalmente os camponeses do Sul. O Parlamento representava os grupos dominantes, legitimados pelo sufrágio (embora restrito) que os elevou ao poder. Neste contexto, as instituições permaneciam frágeis ante possíveis formas de resistência, embora estas também se fragilizavam por falta de uma organização unificadora; deste modo podiam ser combatidas, principalmente por um mecanismo desmobilizador que se tornou comum na política italiana e conhecido como transformismo. Desta perspectiva, a tendência era manter 
as contradições sociais e reduzir os movimentos sociais ao nível primitivo de corporativismo, "no sentido moderno da palavra", ou seja, nos limites das funções econômico-corporativas e não no âmbito mais elevado da consciência política (Q. 14, p. 1743).

No Caderno 10, a propósito do Risorgimento, Gramsci acentua que essa se tornou uma característica das revoluções burguesas europeias do século XIX, a partir de alianças políticas e conciliações entre setores da burguesia com a aristocracia feudal a fim de fazer frente ao movimento operário. As formulações de reformas graduais se tornam comuns evitando, assim, explosões revolucionárias radicais e violentas, como as que aconteceram na França. Tais reformas sociais, geralmente determinadas pelo alto, serviam para modernizar o aparelho de Estado e conservar as classes feudais no aparato governativo (Q. 10, p. 1358). O transformismo se caracteriza pela absorção das eventuais lideranças dos trabalhadores, desmobilizando assim seus movimentos políticos.

Os limites do sistema parlamentar também se colocam a partir de sua função no âmbito da democracia burguesa liberal, organizada em torno de um aparato jurídico que se sedimenta na separação entre forma e conteúdo, ou seja, da perspectiva legal, todos são iguais perante a lei, porém, enquanto a lei não se refere às contradições e desigualdades sociais que caracterizam uma sociedade dividida em classes, a lei não atinge igualmente todos os indivíduos. Entretanto, a separação entre formal e real funciona como mecanismo ideológico e educativo, na medida em que gera a ilusão de igualdade.

O direito não exprime os interesses de toda a sociedade, mas sim da classe dominante, "que 'impõe' a toda a sociedade aquelas normas de conduta que estão mais ligadas à sua razão de ser e ao seu desenvolvimento" (Q. 6, p. 773); o direito, na estrutura do Estado moderno, contribui para a consolidação das relações de hegemonia, visto que sua atividade abrange tanto a sociedade política quanto a sociedade civil, ou seja, o direito atua no âmbito da coerção e da formação do consenso na orientação da conduta de cada indivíduo que não queira sofrer penalidades. A função máxima do direito "é pressupor que todos os cidadãos devem aceitar livremente o conformismo" porque, sendo todos iguais, todos podem aspirar a tornarse dirigentes ou a ascender socialmente. "Este caráter educativo, criativo e formador do direito foi pouco esclarecido por certas correntes intelectuais", tratando-se de um "resíduo do espontaneismo e do racionalismo abstrato", com base num determinado conceito de natureza humana (Q. 6, p. 773-774). 
Interrogar-se sobre o caráter educativo do direito implica entender a força da ideologia na formação do modo de pensar coletivo ou do conformismo social ao qual todos são adaptados; desta forma, o direito atua para a acomodação das classes subalternas ao contexto da hegemonia vigente, bem como à estrutura da democracia burguesa e seu sistema parlamentar. Na medida em que os subalternos limitam suas ações pelas normas legais escritas pelos dirigentes, "conformam-se" (ou adaptam-se) a uma determinada situação que é pressuposta e que delineia seu imaginário não permitindo avançar além dos limites legais. O direito torna-se, então, uma condição para a manutenção da ordem vigente, um condicionador que funciona como uma miragem a delimitar a ação política dos subalternos e a mantê-los na subalternidade.

Esta questão implica mostrar os limites da ideia de igualdade que sustenta o sufrágio universal, na medida em que a desigualdade social instaurada torna essa igualdade uma miragem, ou seja, existe apenas no imaginário social para garantir uma estrutura política desigual. Cabe acentuar que Gramsci não faz essas críticas para desqualificar o sufrágio universal, que foi uma conquista histórica importante, mas para mostrar seus limites no contexto da democracia burguesa; a participação igualitária no sistema representativo é ilusória e tolhe ao homem comum "aquela infinitésima fração de poder que ele possui no decidir sobre o curso da vida estatal” (Q. 13, p. 1624-1625).

Os números têm apenas "um simples valor instrumental, que dão uma medida e uma relação e nada mais. E o que se mede? Mede-se precisamente a eficácia e a capacidade de expansão e de persuasão das opiniões de poucos, das minorias ativas, das elites, das vanguardas, etc.” (Q. 13, p. 1625). O que precisaria ser mais importante que os números é o projeto econômico e social compartilhado, a consciência crítica a determinar os caminhos a seguir. $\mathrm{O}$ aspecto restritivo do sufrágio universal se encontra tanto no fato de direito ao voto a apenas alguns setores da sociedade quanto no ideário liberal que se consolida no senso comum nas crenças na igualdade e na liberdade individual, instrumento mistificador que gera a crença de participação efetiva no processo eleitoral. Este ideário se reforça a partir da estrutura dos partidos políticos que, em geral, se organizam não para cumprir projetos e programas, mas para vencer eleições e legislar em nome dos interesses que financiam suas campanhas.

$\mathrm{O}$ funcionamento do parlamento se adequa à estrutura do Estado no contexto da sociedade capitalista, primeiro, porque não consegue exercer 
as suas funções efetivamente democráticas, ou seja, no interesse de toda a sociedade, porque a própria função representativa fica distorcida no contexto de uma sociedade desigual. Gramsci coloca a questão de procurar saber se "parlamentarismo e regime representativo se identificam e se não existe a possibilidade de uma solução diversa" tanto do parlamentarismo quanto do regime burocrático, com uma nova forma de representatividade (Q. 14, p. 1708).

A questão sobre os limites dos regimes representativos no contexto da sociedade burguesa supõe explicitar que Gramsci tem no seu horizonte a possibilidade de uma forma mais democrática de exercício do poder, como vivenciou na experiência dos Conselhos de fábrica e como defende, no curso dos cadernos, a emancipação intelectual dos grupos subalternos. Os Conselhos concretizaram uma experiência de vida coletiva e de organização dinâmica que articulava, produção, política e educação, entendendo-se que a liberdade individual não se efetiva no individualismo burguês, mas na prática política e na vida coletiva acompanhada pela formação de um pensamento coletivo articulado. No âmbito da organização política dos trabalhadores a educação que relaciona dialeticamente teoria e prática é aquela que pode assegurar o desenvolvimento da personalidade individual a partir do processo de construção da vida coletiva por meio da qual o indivíduo se transforma convivendo com os outros as mesmas experiências.

As observações acima nos permitem mostrar o caráter restritivo das políticas públicas educacionais, que Gramsci evidencia na sua crítica à reforma Gentile. O contexto da estrutura do Estado, que Gramsci define como educador, serve de base para esclarecer os limites do sistema parlamentar na democracia burguesa e seus desdobramentos nas políticas públicas educacionais voltadas para a formação das classes subalternas.

A partir dos pressupostos que sustentam o sistema parlamentar na democracia burguesa, na medida em que se aprofundam as desigualdades sociais, diminuem as possibilidades de participação efetiva das classes subalternas na estrutura política e seu voto serve apenas para referendar as relações de poder vigentes e a permanência de representantes dos grupos conservadores no legislativo. Esses grupos legislam em favor da conservação das relações de poder e do sistema instituído, fato que se reflete nas políticas educacionais. Gramsci constata essa situação na realidade italiana do início do século XX na comparação entre a antiga lei Casati e a reforma Gentile:

A eficácia educativa da velha escola média italiana, como a antiga lei Casati a havia organizado, não se devia procurar (ou negar) na vontade 
expressa de ser ou não escola educativa, mas no fato de que a sua organização e seus programas eram a expressão de um modo tradicional de vida intelectual e moral, de um clima cultural difuso em toda a sociedade italiana por tradições antiguíssimas. [...]. Se não se levam em conta estas condições, criticar os programas e a organização disciplinar da escola quer dizer menos que nada (Q. 12, p. 1543).

Quando as políticas educacionais expressam as condições reais de vida da sociedade, conseguem efetivar projetos e superar crises, porque a participação ativa de alunos e sociedade acontece somente se a escola estiver vinculada à vida e responder aos interesses dos grupos sociais que a frequentam. Gramsci acentua a importância da lei Casati, apesar de esta lei expressar um modo tradicional de vida, na forma como se possibilitava às classes subalternas o acesso às condições de produção de um pensamento autônomo, por meio das disciplinas do currículo. Por exemplo, o "estudo gramatical das línguas latina e grega, unido ao estudo das literaturas e histórias políticas respectivas, eram um princípio educativo" porque contribuíam para explicitar elementos constitutivos da vida e da cultura nacionais (Q. 12, p. 1543).

A concepção pedagógica de Gramsci supõe entender as relações de força que se efetivam em relações de hegemonia, no contexto da qual a escola assume importância na medida em que esta instituição pode articular a formação geral com o ensino profissional, gerando a possibilidade de uma disciplina argumentativa e científica como solução a longo prazo (Q. 28, p. 2330-2331).

A questão de fundo era que a escola não deveria estar voltada a formar visando finalidades práticas imediatas, mas sim dedicada ao "desenvolvimento interior da personalidade, a formação do caráter pela absorção e assimilação do passado cultural da civilização europeia moderna”. Gramsci valoriza inclusive a mecanicidade da aprendizagem dessas línguas, como modo de formar "hábitos de disciplina, de exatidão, de compostura até mesmo física, de concentração psíquica”, enfim, de elementos da formação individual que se pode adquirir somente pela "repetição mecânica de atos disciplinados e metódicos” (Q. 12, p. 1544) ${ }^{1}$.

Estas colocações reforçam a importância da disciplina no processo educativo escolar que, acompanhada de hábitos de trabalho enquanto

1 Gramsci pergunta se um estudioso seria capaz de ficar sentado horas seguidas em processo de pesquisa se não tivesse sido disciplinado na infância, se 'não tivesse assimilado por meio de coerção mecânica, os hábitos psicofísicos apropriados' para, agora, exercer sua profissão (Q. 12, p. 1544). Estas colocações se ampliam no Caderno 22, sobre Americanismo e Fordismo. Abordamos a questão da disciplina em Schlesener (2009). 
atividade teórico-prática no seu conjunto, "criam os primeiros elementos de uma intuição do mundo liberada de toda magia e bruxaria”, condições para o futuro desenvolvimento de uma concepção histórica e dialética do mundo (Q. 12, p. 1541). Supor que este tipo de formação dependa de políticas públicas bem formuladas evidencia a importância da ação dos parlamentares e da participação política consciente das classes subalternas.

A retirada do currículo do estudo da gramática normativa, como aconteceu com a Reforma Gentile, retira das classes populares a possibilidade de ter o aprendizado da língua culta e de sua história e tradições, ou seja, de ter conhecimentos importantes para a sua formação política. A "gramática normativa que, somente por abstração pode ser considerada separada da linguagem viva”, pode fazer apreender a organicidade de uma língua determinada e criar uma "atitude espiritual que torna capaz de orientar-se no ambiente linguístico” (Q. 29, p. 2349).

Excluir a gramática normativa do currículo significa, portanto, restringir as possibilidades de conhecimento para as massas populares e, consequentemente, aumentar as distâncias já existentes entre as classes sociais, visto que as crianças filhas das classes dominantes já aprendem a língua culta no cotidiano da conversação com os pais. Na atitude de Gentile "há muito mais política do que se acredita”, há "o reacionarismo da velha concepção liberal, há um 'deixar fazer, deixar passar' que não é justificado, como era em Rousseau” (Q. 29, p. 2349).

Esta aproximação da concepção liberal com Rousseau identificada na proposta de Gentile é criticada por Gramsci, principalmente porque centrada na espontaneidade da criança. Da perspectiva dialética, "cada geração educa as novas gerações e este processo se apresenta como uma luta contra os instintos ligados às funções biológicas elementares, uma luta contra a natureza, para dominá-la e criar o homem” adaptado à sua época. A espontaneidade é problemática porque a criança acumula percepções e imagens desde que nasce e essas informações se tornam complexas com o aprendizado da linguagem, que as organiza de forma lógica (Q. 1, p. 114). Sem uma orientação precisa, as possibilidades da criança de aprendizagem e de conhecimento se limitam consideravelmente.

Gentile retirou a gramática normativa do currículo da escola italiana, mas defendeu a permanência do ensino religioso que, para Gramsci, se apresenta como a "renúncia (tendenciosa) a educar o povo", de acordo com aquela concepção tradicional de que a religião é a filosofia da infância 
e o povo, como as crianças, precisa ser mantido em sua fase primitiva de compreensão (Q. 11, p. 1367). Do ponto de vista da leitura de Gramsci, a questão da educação no sistema escolar implica a conformação do aluno aos interesses sociais, mas também a sua formação para a emancipação individual e social, visto que se trata das classes trabalhadoras.

Embora Gramsci esteja analisando as condições políticas e sociais da Itália do início do século XX, a situação brasileira neste início do século XXI parece ainda mais conservadora e atrasada que aquela realidade, principalmente se lembrarmos que parlamentares se elegem porque são religiosos e praticam atos de intolerância religiosa no interior do Congresso nacional. Esta situação ainda não se traduziu em políticas educacionais, embora não estejamos distantes disso.

A partir do conceito amplo de educação aqui evidenciado, passamos para a consideração das formas de domínio que perpassam o processo educativo, desde o nascimento da criança, sendo a escola um dos momentos de consolidação das relações de domínio e controle social. Importante salientar que a sociedade vive relações que, muitas vezes, são contraditórias e essa contradições, que se renovam no interior do sistema escolar, podem ser identificadas e transformadas em motivo de ações inovadoras. Tudo depende da proposta de trabalho do professor e do material pedagógico que dispõem para desempenhar essa tarefa.

\section{As formas de domínio que se efetivam pela educação}

O despertar iminente é como o cavalo de madeira dos gregos na Troia dos sonhos (BENJAMIN, 2009, p. 437).

Partimos de uma afirmação de Gramsci sobre a educação anotada no Caderno 1: a 'escola' ou seja, a "atividade educativa direta, é somente uma fração da vida do aluno, que entra em contato com a sociedade" formando critérios a partir destas fontes "[...]'extraescolares', que são muito mais importantes do que comumente se acredita" (Q. 1, p. 114). A educação, portanto, tem uma dimensão política por fazer parte do processo de organização social e de formação do comportamento de acordo com os objetivos e finalidades do projeto econômico e social em curso, entendendo-se política em sentido amplo, a partir da divisão da sociedade em classes sociais antagônicas. Neste contexto, a educação pode se apresentar como um dos mecanismos de assimilação das relações de poder vigentes e de consolidação das formas de domínio. Gramsci acentua esse fato em carta de 11 de abril de 1927: 
Eu julgava que duas obras-primas concentravam a experiência milenar dos homens no campo da organização de massa: o manual do cabo e o catecismo católico. [...]. Cabe acrescentar agora o regulamento carcerário que encerra verdadeiros tesouros de introspecção psicológica (GRAMSCI, 1975d, p. 74).

Poderíamos acrescentar a cartilha, as apostilas e todo o material didático que se utiliza como recurso de aprendizagem nas escolas. Ao lado desses instrumentos, as teorias pedagógicas que os motivam, a própria disciplina exercida a partir da autoridade e do conhecimento do professor, problema que Gramsci aborda no curso de suas cartas e escritos. E Gramsci, na sua perspectiva educativa, considera alguns meios disciplinares (que, no fundo, são coercitivos) importantes no processo pedagógico. A disciplina é importante na aquisição de hábitos e de comportamento, principalmente nos primeiros anos da educação escolar, quando a criança precisa ser iniciada no conhecimento e na vida social. A disciplina não deve tolher as tendências e criatividade da criança, mas deve servir para desenvolvê-las.

As formas de domínio passam pelo adestramento do corpo na adequação ao processo produtivo, fato que Gramsci acentua no Caderno 22, na sua abordagem do taylorismo-fordismo, quando mostra como a racionalização do processo produtivo, acompanhada das transformações tecnológicas e organizativas, exige um dispêndio específico da força de trabalho e uma disciplina do gesto, com uma forma específica de uso da capacidade intelectual do trabalhador, como parte de sua formação.

Já no primeiro parágrafo do Caderno 22 Gramsci elenca uma série de pontos para abordar ao longo do caderno e verificamos que a maioria, senão todos, implicam uma forma coercitiva de formação, no sentido de adaptação do homem às necessidades do trabalho no modo de produção capitalista: a mudança da estrutura econômica visando redefinir a acumulação e distribuição do capital financeiro, a questão sexual, a racionalização da composição demográfica (controle da natalidade) na Europa, a questão jurídica, a dos altos salários na indústria fordista, a psicanalise como forma de coerção moral exercida sobre os indivíduos (Q. 22, p. 2140).

Essas questões assumem enorme relevância quando se trata de refletir sobre a educação e sobre a escola. A eficácia política da ideologia se apresenta no modo como se abordam os assuntos no processo de aprendizagem. Palavras como ordem, liberdade, sexualidade, etc., se forem apresentadas sem o seu significado histórico, ou seja, se forem abordadas como se fossem naturais, reforçam as formas de dominação vigentes. Gramsci apresenta um 
exemplo esclarecedor quando se refere à ideia de ordem: a "ordem presente se apresenta como algo harmoniosamente coordenado", expressando a "imobilidade estática" que exclui toda a dinâmica da vida (GRAMSCI, 1978c, p. 5). Quando um conceito se naturaliza, perde-se a compreensão de sua historicidade e a ideia adquire grande força de conservação, tornando-se verdade absoluta e eterna. Tudo o que se contrapõe a essa ideia cristalizada passa a ser considerado erro; perde-se a dimensão do movimento da vida e se tem dificuldade de aceitar o diferente ou mesmo o contraditório.

Esses pontos trazem implícita a questão ideológica no contexto das relações capitalistas de produção e de sociabilidade, na medida em que ocultam o caráter de classe do conhecimento. Poderíamos acrescentar a legislação que regulamenta a estrutura familiar, a formação religiosa, o controle do tempo e a sua distribuição ao longo da vida, o tratamento do idoso, etc., em suma, todas as formas sociais que determinam a formação e o modo de vida desde o nascimento até a morte.

A questão da educação sexual foi tratada por outros autores na historia da filosofia moderna. O silenciamento sobre o corpo e a percepção ou sobre as diferenças com relação à sexualidade no processo educativo são formas veladas de censura e de controle que marcam a subjetividade da criança e suas capacidades de expressão ${ }^{2}$.

Gramsci (Q. 22, p. 2150), no Caderno 22 aborda alguns aspectos da questão sexual e de sua repressão no contexto do desenvolvimento das sociedades, principalmente no tratamento da mulher e dos idosos, concluindo que "não se pode desenvolver o novo tipo de homem exigido pela racionalização da produção e do trabalho" sem que se regulamente e se racionalize também o instinto sexual.

Neste contexto, a questão de gênero se vincula à sexualidade da mulher e sua função de reprodução no âmbito de relações econômicas voltadas para a acumulação do capital, que determinam o relacionamento sexual: a esta questão vincula-se a da "formação de uma nova personalidade feminina" pela qual a mulher precisa alcançar "sua real independência em face do homem, bem como um novo modo de conceber a si mesma e a sua função nas relações sexuais” (Q. 22, p. 2149). Se pensarmos que Gramsci acentua

2 Como exemplos, citamos Beauvoir (1983) recorda sua infância e a sua admiração por sua família, depois de tanto controle, deixá-la morar sozinha em Paris, compreendendo, mais tarde, que havia interiorizado o controle. Também Foucault (1977), a partir de outro paradigma, acentua as graves consequências que o controle e a disciplina autoritários geram no processo de formação do homem moderno. 
essa necessidade no início do século XX, tem uma concepção avançada para o seu tempo.

Essa questão é fundamental da perspectiva educativa, visto que a história da indústria vem acompanhada por um processo continuado "doloroso e sangrento, de sujeição dos instintos” a normas e hábitos de ordem, que visam "formas sempre mais complexas de vida coletiva" que, no contexto do industrialismo, são necessárias para o maior rendimento da força de trabalho. A coerção brutal para a afirmação do "domínio de um grupo social sobre todas as forças produtivas da sociedade" tem sido recorrente na história. A “seleção ou 'educação' do homem adequado aos novos tipos de civilização" a partir das necessidades das novas formas de produção e de trabalho, aconteceu com o emprego de brutalidades inauditas" eliminando os mais frágeis ou os que resistem ao processo de absorção. E "quando a pressão coercitiva é exercida sobre toda a sociedade, [...] desenvolvem-se ideologias puritanas", por meio das quais se estabelece a "forma exterior da persuasão e do consenso ao uso intrínseco da força” (Q. 22, p. 2160-2161). Quando o resultado é alcançado, ou seja, quando se interioriza o comportamento, não se torna mais necessária a pressão.

A educação repressiva no âmbito do processo social se estende para a escola enquanto formadora de hábitos e continuadora da adaptação do indivíduo aos interesses da sociedade. Compreender e superar esta situação implica criar, a partir da organização política dos grupos subalternos, um novo contexto ideológico, uma nova concepção de mundo, uma nova ética no contexto de novas relações de hegemonia.

Por todas as observações acima, entende-se que Gramsci não se coloca contra esse processo educativo, não que defenda a coerção, mas acentua que toda mudança social exige algum tipo de pressão sobre os homens no sentido de adaptá-los ao novo. Conforme Remo Bodei (1997, p. 183):

O problema da disciplina certamente varia com base na direção na qual tende, ainda que ela contenha em si um gérmen perigosíssimo que mata $o$ senso crítico, a inteligência e a vontade de quem é constrangido a praticá-la. O crer e o obedecer submetendo-se a uma disciplina aceita, não representa necessariamente para Gramsci uma forma de 'servidão voluntária'.

Compreender a nova noção de disciplina proposta por Gramsci implica entender sua necessidade na produção de um novo projeto social e político que tenha no horizonte uma nova concepção de mundo e de uma efetiva democracia. Entretanto, as possibilidades de controle social são fortes e constituem um verdadeiro problema para definir a educação. Os limites 
entre coerção e disciplina são frágeis e, se relacionados com a questão da ideologia enquanto absorção de ideias que se traduzem em comportamentos, tem-se que perguntar também se a persuasão não traz em si um elemento de coerção.

A formação de uma nova sociabilidade se apresenta como um processo difícil e contraditório, que as classes subalternas precisam enfrentar e, para tanto, precisam superar todas as formas de obediência e submissão que lhe são impostas no contexto do modo de produção capitalista e a disciplina se torna um instrumento fundamental para a realização deste projeto.

A escola que Gramsci chama de tipo "humanista”, precisa desenvolver no indivíduo a cultura e o "poder fundamental de pensar de saber orientarse na vida” (Q. 12, p. 1530). Essa característica da escola tradicional foi-se perdendo com as novas profissionalizações inseridas sem um planejamento claro e preciso nas políticas públicas italianas; para Gramsci, a "crise do programa e da organização escolar, ou seja, da orientação geral de uma política de formação dos modernos quadros intelectuais" era um dos aspectos da crise orgânica vivida naquele momento. A implantação da escola técnica colocou em debate o principio de formação cultural geral "com base na tradição greco-romana"; a tendência geral era abolir a escola "formativa" ou manter "um exemplar reduzido para uma pequena elite" não destinada a exercer funções profissionais (Q. 12, p. 1531). Gramsci identificava, na Itália do início do século XX, uma tendência que seria geral no mundo capitalista com a implementação de novas tecnologias de produção.

Ao decidir sobre programas e organização escolar, o Estado exerce o seu poder de controle do sistema escolar conforme os objetivos da estrutura econômica e produtiva, no sentido de formação de mão de obra, antes que formar indivíduos pensantes. Essa forma externa de domínio se completa com a determinação de programas e de material didático, como orientação ideológica preferencial ${ }^{3}$. Esse modelo de escola insere-se no contexto educativo mais amplo, que é o de preparar as classes trabalhadoras para os objetivos da produção.

Ao lembrar do manual do cabo, do catecismo católico, muito importante na Itália, e o controle exercido no sistema carcerário, Gramsci acentua

3 Tomemos como exemplo os livros de história e como apresentam a questão da revolução: por que se valoriza tanto a Revolução Francesa e nem sequer se cita a Revolução de 1848 ou a comuna de Paris? Porque a primeira iniciou o processo de construção da ordem burguesa, enquanto a segunda e a terceira foram revoluções operárias por uma República Social ou pelo socialismo, contra a ordem burguesa, ou seja, trata-se de uma leitura que não é neutra e sim serve para legitimar o conflito que instaurou a ordem burguesa e omitir as novas formas de luta de classes produzidas a partir desta ordem. 
as formas de educação repressiva e de formação ideológica que podem ser articuladas ao sistema escolar, embora este seja mais flexível no processo de formação. No contexto da teoria política gramsciana, todo processo de educação tem uma característica ideológica fundamental para a conservação da ordem instituída. A defesa de uma escola que contemple a cultura geral visa a formação das classes trabalhadoras para a sua emancipação política no contexto da luta de classes.

\section{A noção gramsciana de ideologia e o discurso conservador}

As ideias dominantes de uma época são sempre as ideias da classe dominante (MARX, 1978, p. 111).

Estamos vivendo um momento de retorno das ideias mais conservadoras a respeito do que seja o pensamento e sua expressão da realidade efetiva. Trabalhos acadêmicos defendidos e aprovados diante de bancas que se dizem de renome defendem a neutralidade de suas abordagens, contra um discurso que denominam ideológico e doutrinador. Cabe-nos explicitar, a partir dos escritos de Marx e de Gramsci, o que se efetiva de fato como ideológico, a fim de rebater a ideia de um pensamento neutro. Numa sociedade dividida em classes sociais antagônicas, marcada pela exploração da força de trabalho e uma concentração fabulosa de rendas, que acentua desmesuradamente a desigualdade social, é fantasmagórica a defesa da neutralidade axiológica.

Da perspectiva da filosofia da praxis, neste contexto social a noção de verdade universal é abstrata, porque toda verdade é histórica e expressa um ponto de vista de classe e, como acentua Marx em A Ideologia Alemã, a "classe que dispõe dos meios de produção material dispõe igualmente dos meios de produção intelectual” (MARX, 1976, p. 55-56). Retomando a leitura gramsciana, a produção intelectual elaborada por pensadores que se constituem uma elite representante da classe dominante, serve para manter e ampliar as relações de domínio que se efetivam como hegemonia. $\mathrm{E}$ os meios de produção intelectual também servem para concretizar tais relações, veja-se o que dissemos a propósito da linguagem e dos meios de comunicação de massa.

A questão da ideologia merece ser retomada aqui porque a educação escolar, aliada ao senso comum veiculado nos meios de comunicação de massa, além da formação recebida na família e nas igrejas, em geral prepara 
as crianças para a vida passiva característica dessa estrutura social. As perspectivas de abordagem da ideologia colocadas por Gramsci são variadas, indo desde a crítica a uma noção de objetividade exterior (tão cara hoje, aos conservadores), até a inversão da noção de verdade, passando pela explicitação da historicidade de toda produção teórica, para mostrar que a ideologia e a doutrinação estão da parte dos dominantes e não dos dominados.

Tendo como pressuposto a historicidade do pensamento, toda verdade que se acredita eterna e absoluta apresenta-se como um mito a ser desmistificado. No movimento histórico, todo pensamento tem origens práticas e expressa um valor provisório. Isso é importante no desenvolvimento de uma teoria pedagógica e no processo de aprendizagem, para não se cair em doutrinação, como acusam os conservadores sem perceber que, eles próprios, no momento em que afirmam a verdade absoluta de sua posição, estão sendo doutrinadores. Doutrina que se mantém ainda no século XXI é o positivismo que, assimilado pelo senso comum, dificulta qualquer processo de aprendizado que aborde o conhecimento de outra perspectiva.

Adquirir clareza do conjunto de relações sociais nas quais se está inserido e superar níveis de compreensão dessa realidade e perceber que fazemos parte de um grupo social em movimento, superando interesses imediatos para entender o movimento histórico em suas contradições não é uma tarefa fácil. Superar um conhecimento que se funda na lógica formal para apropriar-se de um pensamento dialético, cujo conteúdo de verdade se encontra na articulação entre teoria e prática, articulação esta permanentemente renovada no movimento da história, exige esforços inusitados.

A filosofia da praxis coloca a questão do que é a verdade e demonstra que esta não é um fato apenas lógico, mas sim um fato essencialmente político, ou seja (e aqui o que assusta os conservadores), é no enfrentamento dos conflitos sociais, no confronto das forças em luta, que se constrói a verdade que expressamos em teoria, mas que nasce da prática e da tentativa de subverter esta prática. E esta verdade é sempre parcial e provisória, feita de luzes e sombras, a partir de perspectivas porque é uma verdade histórica, centrada na luta de classes, cuja divisão precisa ser superada para que se possa, enfim, construir uma verdade universal.

Dessa perspectiva, toda filosofia é também uma ideologia, inclusive a filosofia da praxis. Mas é uma ideologia com um teor de verdade diverso do positivismo, do idealismo ou de qualquer outra metafisica: trata-se de uma filosofia que visa a esclarecer os subalternos dos grilhões invisíveis 
que os prendem, de modo consciente e inconsciente, e que os reduzem a seres passivos e obedientes; visa a esclarecer para que possam emancipar-se e conquistar a liberdade. As ideologias dominantes, ao contrário, servem como "instrumentos práticos de domínio político sobre o restante da sociedade", para submeter ao trabalho e ao modelo social vigente; sua força de dominação se encontra na sua fingida neutralidade, na sua capacidade de obscurecer as relações reais mistificando-as e escondendo os elos de submissão que existem na realidade e que servem para manter a ordem instituída. Nesse contexto, como acentua Gramsci, as ideologias não são ilusões nem aparências, mas possuem um conteúdo político que se traduz na forma como se tornam instrumentos de direção política, ou seja, "são fatos históricos reais, que é necessário combater e explicitar na sua natureza de instrumentos de domínio, não por razões de moralidade, etc.” (para os conservadores a moralidade é anterior e superior à política), "mas precisamente por razões de luta política”, para tornar os subalternos intelectualmente independentes (Q. 10, p. 1319).

Resumindo, em uma sociedade dividida e profundamente desigual como a sociedade capitalista, o pensamento expressa, queiramos ou não, interesses de parte da sociedade, porque ela se encontra dividida em classes sociais antagônicas. A diferença é que o pensamento hegemônico, porque da parte das classes dominantes, mascara a realidade, transforma a sua visão parcial em visão universal e submete os governados convencendo-os dessa universalidade. A filosofia da praxis, enquanto teoria das contradições, é expressão da realidade dos grupos subalternos e visa a esclarecer esses grupos sociais da realidade da dominação para que tenham acesso aos instrumentos do conhecimento para a sua emancipação e para a sua efetiva liberdade.

Retomemos, agora, a questão da linguagem: o poder mistificador e de ocultamento dos interesses por meio da ideologia se manifesta no uso da linguagem. O discurso "politicamente correto", traduz-se em uma forma de censura, que se torna, no curso do tempo, autocensura, ou seja, valores e princípios que se escondem em conceitos são assimilados formando o senso comum e ocultando as contradições do real. Como acentua Dias (2012, p. 36-37), como exemplo: "apagar formas ofensivas" tidas como "racistas" nos escritos como Monteiro Lobato, funciona para "ocultar as diferenças reais".

A pretexto do pagamento da dívida histórica da escravidão - dívida dos dominantes - passa-se a uma culpabilização histórica dos próprios dominados (a culpa é genericamente dos brancos, mesmo daqueles tão 
oprimidos quanto os negros descendentes (ou não) de escravos. Mudamse as palavras, muda a realidade? Palavras passam a ser substituídas: não mais negros, mas afrodescendentes. Políticas focalizadas (que em nada alteram a dominância burguesa) passam a ser formas compensatórias daquelas culpas genéricas ao contrário das políticas universais que são apresentadas como incapazes de resgatar as diferenças históricas e criminosamente construídas (DIAS, 2012, p. 37).

Trata-se de uma forma de educação pelo silenciamento ou ocultamento das contradições reais que caracterizam a história da dominação burguesa. ${ }^{4}$ A educação pelo silêncio funciona sempre como uma forma de censura que culpabiliza de modo generalizado, como acontecia, ainda em meados do século XX, com a educação sexual das crianças. Na família nada se dizia e nada se explicava porque "era feio", "era mau" e as crianças, que não aprendiam em casa, iam aprender na rua, correndo sérios riscos em seu processo de educação.

A censura foi tema dos escritos políticos de Gramsci, tanto no contexto da Guerra de 1918 quanto com referência ao fascismo. Em Rabiscos, publicado em Scritti Giovanili (GRAMSCI, 1975, p. 340-42), nosso autor acentua as dificuldades de encontrar um equilíbrio na escrita entre "as necessidades da própria sinceridade e as agressões irracionais da censura", que entende como um abuso de autoridade de quem, detendo por um momento um poder, quer deixar seu vestígio, mesmo que seja o de sua injustiça.

E o resultado de qualquer ação censora constante e recorrente resulta em interiorização do controle pela parte censurada que, no caso de Gramsci (1975, p. 342), jornalista, procurava produzir um discurso capaz de elidir o censor. A "caneta continua a produzir rabiscos, esperando, porque sente que esta barbárie (a confusão nos critérios, o arbítrio, o abuso são barbáries) se esgotara na própria raiva”.

Na educação escolar a adaptação ao processo social acontece por meio do aprendizado das palavras e da explicitação de seus significados; ditas ou veladas, as palavras podem encobrir mais do que desvelar sentidos, cumprindo uma grande função na consolidação de uma ideologia. Num processo de aprendizagem que vise a emancipação do aprendiz, a compreensão da palavra precisa ir além do seu significado abstrato, para atingir sua significação política e concreta, isto é, precisa ser entendida em sua dimensão

4 Nesse contexto, a linguagem nao explicita o sentido, mas mistifica a realidade ocultando os conflitos que a constituem, $\mathrm{O}$ discurso politicamente correto não diz pobre, miserável, faminto, mas "indivíduo em condições de insustentabilidade"; no lugar de prisioneiro, encarcerado, se diz "privado de liberdade". Trata-de de um discurso que mistifica as relações sociais, a censura e a dominação. 
ideológica, no teor de verdade que ela expressa e para quem este significado interessa, porque nenhum discurso é neutro em uma sociedade de classes.

Educar para a emancipação intelectual, com futuros desdobramentos na prática do aprendiz, implica mostrar os limites do discurso dominante na sua pretensão de verdade absoluta e universal, a fim de possibilitar ao educando a formação de um pensamento autônomo e independente. Se traduzirmos educando por grupos subalternos, significa dar-lhes os instrumentos de emancipação política a partir do teor de verdade da filosofia da praxis enquanto teoria das contradições.

Realizar esta tarefa implica persistência e metodologia; Gramsci faz algumas observações sobre a questão do método de aprendizagem, que podem ser importantes para o trabalho do professor na escola ou do dirigente no partido:

No ensino da filosofia dedicado não a informar historicamente o discente sobre o desenvolvimento da filosofia passada, mas para formá-lo culturalmente, para ajudá-lo a elaborar criticamente o próprio pensamento e assim participar de uma comunidade ideológica e cultural, é necessário partir do que o discente já conhece, de sua experiência filosófica (após ter demonstrado que ele tem uma tal experiência, que ele também é um 'filosofo' sem o saber) (Q. 1, p. 148).

O ponto de partida é o senso comum, ou seja, as "informações soltas e fragmentárias”, sem qualquer preparação metodológica ou crítica que fazem parte do pensamento do discente ou do subalterno (Q. 1, p. 148). Sabe-se que o senso comum se compõe do que existe de mais variado e contraditório entre si, ou seja, de todas as informações que o indivíduo acumula ao longo de sua vida, desde o que recebe da tradição por meio da família e da religião até o conhecimento cientifico mais avançado em dados fragmentados e simplificados que recebe pelos meios de comunicação de massa. Esse conjunto lhe fornece as condições de entender a política, a ética e a moral, a partir do ideário mais recente das classes dominantes. Iniciar desse ponto significa partir das aparências para mostrar seus limites e contradições, entendendo-se o ato pedagógico como pressupondo uma opção política. Criticar o nosso senso comum significa tornar nossa concepção de mundo "coerente e unitária elevando-a ao ponto atingido pelo pensamento mundial mais desenvolvido”. (Q. 10, p. 1371).

A questão política expressa-se no fato de pressupor que a sociedade se divide em classes sociais antagônicas que sustentam a "existência de governantes e governados, dirigentes e dirigidos. Toda a ciência e a arte 
políticas se baseiam neste fato primordial e irredutível” (Q. 15, p. 1752) e que garantem a conotação política de todas as relações vividas na sociedade.

\section{A educação como forma de emancipação para os trabalhadores}

A história pedagógica demonstra que cada classe que se preparou para a conquista do poder, tornou-se apta mediante uma educação autônoma. A primeira emancipação da servidão política e social é a do espírito (GRAMSCI, 1982, p. 643).

A educação perpassa os escritos de Gramsci e a citação acima foi retirada de um escrito de 1916 intitulado A primeira pedra, a propósito de um Congresso realizado em Milão sobre os problemas da educação popular. Conforme o artigo, o evento reuniu pedagogos de diversas tendências, além de fisiólogos, economistas e parlamentares para discutir como deveria ser a educação do povo na escola italiana. E muitas coisas foram ditas e muitas promessas feitas naquela ocasião. Gramsci aproveita o momento para colocar as bases de uma nova educação escolar que realmente interesse aos trabalhadores, visto que as classes dirigentes "querem impor às grandes massas de trabalhadores rurais e urbanos um plano de educação que forme um estado de consciência e uma mentalidade conforme os interesses dominantes", o que parece "muito natural e toda a história das instituições pedagógicas a confirma” (GRAMSCI, 1980, p. 642).

Gramsci acentua que esta questão é tão importante que, na Itália, a "escola foi disputada por duas forças diversas: a Igreja e a Maçonaria" (se pensarmos na nossa realidade, os interesses do capital e a privatização da educação). O povo, porém, tem outros interesses e precisa de uma escola laica, de educação civil; o "programa de educação do proletariado deve ser formulado e efetivado por órgãos que o próprio proletariado constituiu em defesa de seus próprios interesses". O problema da educação é um problema político e "um problema de classe e só pode ser resolvido do ponto de vista de classe". E termina este belo artigo conclamando: Temos que tirar das mãos das classes dirigentes a educação dos trabalhadores, como o primeiro e decisivo passo para uma nova era (GRAMSCI, 1980, p. 643).

Trata-se de uma questão fundamental para a autonomia das classes trabalhadoras, como o primeiro passo para a emancipação política. A partir dessa leitura, critica-se Gramsci nos Escritos de militância política por valorizar excessivamente a cultura e o processo educativo como condição para a revolução. Esse tema retorna com toda a sua força nos Cadernos, 
principalmente nos escritos referentes à crítica às pedagogias que sedimentam a escola burguesa e nas breves observações sobre a escola única. Cabe acentuar ainda a importância que Gramsci atribui ao trabalho político dos intelectuais e também à formação do partido.

A questão da educação implica uma organização partidária interna que viabilize a permanente participação de todos nas decisões numa relação dialética que permita a qualquer membro se tornar dirigente, ou seja, Gramsci redefine a noção de democracia no interior do partido acentuando que este não deve seguir o modelo parlamentar burguês, mas deve criar uma nova experiência democrática que possibilite às massas atingir um nível superior de autonomia política.

Toda a análise gramsciana da política é perpassada pela questão da educação. Do mesmo modo, o seu trabalho de historiador, tem como pano de fundo a formação das classes trabalhadoras para a sua luta política e cultural. A leitura gramsciana da história moderna evidencia a construção da hegemonia pela burguesia ascendente em sua capacidade política e ideológica de absorver as demais classes sociais envolvendo-as em seu projeto. Neste movimento de construção da hegemonia, a política e a cultura transformam-se em instrumentos de domínio: “[...]'Estado' significa especialmente direção consciente das grandes multidões nacionais”; isso implica "um 'contato' sentimental e ideológico com tais multidões e, em certa medida, simpatia e compreensão de suas necessidades e exigências”. Esse contato se efetiva por meio da cultura, da arte, da literatura, ou seja, pela atuação dos intelectuais. Na Itália, ocorre a "ausência de uma literatura nacional-popular", o que demonstra a "ausência de preocupação e de interesse por estas necessidades e exigências, deixando o 'mercado' literário aberto a influências de grupos intelectuais de outros países”. [...] “Assim o povo italiano se apaixonou, por meio do romance histórico-popular francês [...] pelas tradições francesas, monárquicas e revolucionárias”, ou seja, "apaixona-se por um passado que não é seu, serve-se na sua linguagem e no seu pensamento de metáforas e referências culturais francesas, etc., é culturalmente mais francês que italiano" (Q. 23, p. 2197).

Em se tornando instrumentos de hegemonia, a política e a cultura assumem novas dimensões no contexto da luta de classes, assim como a própria ideologia enquanto prática de poder. Conforme Burgio (2003, p. 99), na comparação com as sociedades anteriores, na sociedade moderna a "violência migra das relações de comando político para as relações de produção, na medida em que estas tornam-se fundamento da ordem social”. 
Podemos acrescentar que, no âmbito das relações econômicas, a violência se mascara com apoio da ideologia, que forma a nova individualidade. Nas sociedades antigas, o escravo ou o servo de gleba sabiam que eram explorados em seu trabalho. $\mathrm{O}$ assalariado do mundo moderno acredita que é justamente recompensado pelo seu trabalho. Esta mudança de percepção do trabalhador tem como base a forma como o modo de produção capitalista controla o tempo de trabalho e, com ele, o tempo de vida e o modo de pensar de toda a sociedade, ou seja, o modo como se articulam o econômico, o político e o ideológico por meio da formação da subjetividade. $\mathrm{O}$ fato de se fundar na produção e consumo de mercadorias faz com que, na sociedade capitalista, o tempo seja reduzido aos objetivos da produção e da acumulação do capital; como diz o ditado popular, tempo é dinheiro. A serviço deste novo modo de ser está a educação formal, a estrutura urbana, a vida familiar e a cultura em geral ${ }^{5}$.

Um tema relevante para explicitar a questão da educação perpassa a reflexão de Gramsci sobre os caracteres italianos, entre eles a ideia generalizada de que os italianos são individualistas. E Gramsci explicita os significados possíveis de individualismo e seus desdobramentos na ação política. "Não participar ativamente da vida coletiva" não significa, necessariamente, não ser partidário, mas pode significar que, ao "partido e ao sindicato 'modernos', assim como foram elaborados pelo desenvolvimento das forças produtivas mais progressivas, 'preferem' formas organizativas de outro tipo", como as máfias, as camorras, etc. "Qualquer nível ou tipo de civilização tem o seu 'individualismo', ou seja, uma posição e uma atividade peculiares dos indivíduos singulares nos seus quadros gerais”. Esta situação depende tanto da inserção do indivíduo na estrutura econômica quanto de sua formação política e cultural. Na Itália, a "razão deste estado de coisas tem origens históricas distantes" e se esta situação ainda se mantém, a responsabilidade é dos grupos dirigentes nacionais (Q. 6, p. 815) ${ }^{6}$.

\footnotetext{
5 Abordamos a questão do tempo na sociedade capitalista no livro Os tempos da História - leituras de Walter Benjamin. Brasília: Liber Livro, 2011. Basicamente os capítulos II e VI.

6 "Não participar ativamente da vida coletiva, isto é, da vida estatal [...] significa, talvez, não ser 'partidário', não pertencer a nenhum grupo constituído? Significa o 'esplêndido isolamento' do indivíduo singular, que conta somente consigo mesmo para criar a sua vida econômica e moral? De modo nenhum. Significa que ao partido político e ao sindicato econômico 'modernos', assim como foram elaborados pelo desenvolvimento das forças produtivas mais progressivas, 'prefere-se' formas organizativas de outro tipo, precisamente do tipo 'submundo', ou seja, os grupelhos, as camorras, as máfias, sejam populares ou ligadas à classe alta, Qualquer nível ou tipo de civilização tem o seu 'individualismo', ou seja, uma posição e uma atividade peculiares dos indivíduos singulares nos seus quadros gerais. [...] A razão deste estado de coisas tem origens históricas distantes e da manutenção desta situação é responsável o grupo dirigente nacional” (Q. 6, p. 815).
} 
Entendemos que, de qualquer parte que abordemos os escritos do cárcere, a questão de fundo é sempre a educação na sua perspectiva geral: o problema que Gramsci coloca a partir desta análise do significado de individualismo é saber "se tal situação pode ser superada com métodos de centralização estatal (escola, legislação, tribunais, polícia) que tendam a nivelar a vida" conforme a formação de um tipo nacional (Q. 6, p. 815). Ou seja, a educação pode ser efetuada pelos meios estatais em função dos objetivos hegemônicos ou do projeto de sociedade das classes dominantes.

Gramsci acentua a complexidade desse processo e esclarece: uma nova construção social deve "surgir de baixo, na medida em que todo um estrato nacional, o mais baixo econômica e culturalmente, participe a um fato histórico radical" que envolva "toda a vida do povo e ponha cada um, brutalmente, diante das próprias responsabilidades inderrogáveis”. O erro histórico da classe dirigente italiana foi ter "impedido sistematicamente que um tal fenômeno acontecesse no período do Risorgimento" e de ter agido no sentido da continuidade e "manutenção de uma educação cristalizada, do Risorgimento em diante” (Q. 6, p. 816). Em outras palavras, o ponto central para as classes trabalhadoras é sempre a revolução e essa se apresenta como fruto de um processo educativo.

Desta perspectiva, a educação faz parte de todo o processo de organização política e de formação de uma nova concepção de mundo. Aos limites e possibilidades da escola formal, Gramsci acrescenta todas as instituições educativas possíveis a partir dos movimentos sociais organizados pelas classes subalternas. Neste contexto, trata-se de considerar que:

a) a educação realiza-se na vida e a escola é apenas uma de suas instâncias; para Gramsci, a educação realiza-se ao longo da vida enquanto um processo de conhecimento de si e do mundo por meio do qual construímos a nossa identidade e nos inserimos no movimento da vida social e política. A educação formal em geral visa a responder as exigências materiais e simbólicas necessárias para a manutenção do processo de dominação do capital, de acordo com padrões determinados de ensino e aprendizagem, sempre renovados e ampliados para responder às necessidades da produção e não do relacionamento e da realização dos indivíduos.

b) a escola existe para cumprir os objetivos colocados pela estrutura social (formar para o trabalho), embora as contradições sociais permitam ampliar os caminhos de aprendizagem; a escola tem a função de formar para o trabalho numa sociedade marcada pela divisão social, limite no qual atua a escola 
pública. Explicitar as contradições e as correlações de forças que permeiam o social se apresenta como o grande desafio, que exige a inserção de novos métodos de ensino e de formação continuada dos docentes, a fim de criar as condições de uma formação integral. Formar novas subjetividades capazes de reconhecer suas raízes sociais e culturais a fim de compreender a sua inserção no mundo, esse poderia ser o objetivo primordial da escola pública.

A partir desse contexto, quais as condições sociais e políticas para concretizar o ideal emancipatório que se propõe como objetivo? Para Gramsci, na realidade italiana do início do século XX, esse objetivo se encontrava no horizonte das lutas das classes trabalhadoras, visto que educação e emancipação são conceitos que, no contexto do materialismo histórico, deveriam ser análogos ou vinculados em relação de semelhança e completude: a educação deveria ser sempre emancipadora. Mesmo nos limites da sociedade capitalista, as classes subalternas não podem abrir mão da educação formal, simplesmente porque, para enfrentar a luta pela hegemonia, precisam entender as formas de dominação a que estão submetidos e isso só é possível pelo acesso ao conhecimento historicamente produzido.

O projeto social moderno, das classes dominantes, direciona as políticas educacionais voltadas para a educação popular a fim de cumprir os objetivos de consolidação da hegemonia. Se a educação popular é tão importante para as classes dominantes a ponto de ser o "traço mais característico ao qual todos os outros estão subordinados" e motivo de disputa entre Estado e Igreja na Itália, imaginemos para as classes subalternas (Q. 7, p. 930). Assim como no processo de manutenção da hegemonia burguesa, todo o processo de organização política visando a conquista da hegemonia pelas classes subalternas precisa ter como suporte a educação.

\section{A educação escolar, a linguagem e a ideologia}

A escola única, intelectual e manual, tem a vantagem de colocar a criança em contato ao mesmo tempo com a história humana e com a história das 'coisas' sob o controle do professor (Q. 1, p. 114).

A epígrafe acima conclui uma breve reflexão sobre as "origens históricas precisas de alguns princípios das pedagogias modernas”, evidenciando os modos como tais ideias se aplicam no processo educativo, muitas vezes de forma equivocada porque não se tem em conta as condições históricas e as polemicas que geraram as teorias. Um exemplo de Gramsci são as ideias de Rousseau, que originariamente "foram uma reação violenta à escola e aos métodos pedagógicos dos jesuítas”, o que pode ser considerado um progresso. 
Mas posteriormente as interpretações tomaram outros rumos dando "lugar a curiosas involuções (nas doutrinas de Gentile e de Lombardo-Radice). A espontaneidade é uma destas involuções” (Q. 1, p. 114). Já assinalamos que a escola deve assumir uma parte do processo educativo, que acontece ao longo da vida, desde o nascimento até a morte e as demais instituições sociais tem uma grande importância neste processo. Gramsci defendia a educação enquanto um processo formativo que exige disciplina tanto de quem aprende quanto de quem ensina, disciplina entendida como orientação apontando direções e não como controle autoritário.

Ao abordar as várias possibilidades experimentadas por pedagogias modernas, a questão de fundo, para Gramsci, é "criar um tipo de escola que eduque as classes instrumentais e subordinadas a uma função dirigente na sociedade", ou seja, trata-se de formar um coletivo e não apenas desenvolver alguma capacidade individual (Q. 9, p. 1183). Pensar na formação coletiva implica acentuar o caráter político do processo educativo e a importância, para as classes subalternas, de universalizar conhecimentos adquiridos, a fim de que superem a fragmentação de seu modo de pensar (Q. 11, p. 1366-8). E, principalmente, entender que a escola é um dos espaços de formação crítica, na medida em que a filosofia da praxis ou a dialética, como metodologia e critério de interpretação da realidade, possibilitam esse tipo de formação.

Nesta perspectiva, uma abordagem dialética vai muito além das teorias pedagógicas positivistas e mesmo das pedagogias crítico-reprodutivistas, porque a escola, embora tenha objetivos limitados na sociedade capitalista, abre possibilidades de superar estes limites e criar condições de acesso com qualidade ao conhecimento historicamente produzido, essencial para consolidar a personalidade.

Para tanto, precisamos renovar a escola por dentro, questionando currículos, métodos de ensino, fragmentação do conhecimento, objetivos das políticas públicas que retratam projetos de governo e não projetos de sociedade; seria a tarefa inicial no Brasil, a fim de recuperar as condições de qualidade do ensino ministrado. Essa é uma tarefa que em algum momento precisa ser enfrentada tendo como pressuposto a compreensão do todo para manter as possibilidades de uma crítica. Para Gramsci, "as ideias são grandes enquanto são exequíveis”, ou seja, enquanto tornam clara uma situação real e enquanto "mostram concretamente o processo de ações através das quais uma vontade coletiva organizada traz à luz estas relações" e, trazendo à luz, as criam ou as destroem, substituindo-as (Q. 8, p. 1050). 
A importância da educação escolar da perspectiva que aqui abordamos se apresenta na possibilidade de o aluno se apropriar da linguagem e dos códigos de argumentação, para pensar de modo crítico, desconstruindo o discurso ideológico dominante. A aprendizagem da linguagem se torna essencial quando se entende que a hegemonia se consolida pela formação do consenso passivo e que esse poder das classes dominantes se ampliou de forma inusitada com a inserção das novas tecnologias de comunicação. As classes populares, para se organizarem na luta pela hegemonia, precisam se reconhecer no movimento contraditório de construção da sociedade e, para isso, necessitam dominar a linguagem para enfrentar o dominador no seu terreno.

A linguagem é importante para organizar e expressar ideias inovadoras. A educação é sempre política, assim como a linguagem. Numa sociedade desigual não se pode educar sem tomar partido, ou seja, sem mostrar aos alunos as contradições que permeiam a vida da sociedade. Todas as decisões a respeito da estrutura escolar, o currículo, as disciplinas a serem ensinadas ou a serem retiradas do currículo implicam posições políticas que, evidentemente, não aparecem na formulação das propostas curriculares, mas as sustentam, porque os currículos expressam objetivos que são, indiretamente, expressão de interesses de classe.

Defender uma escola sem partido ou sem ideologia é defender uma educação despolitizada que esconde a política mais conservadora que se possa imaginar porque, em nome da neutralidade do conhecimento, se apresenta a seletividade de caráter político conservador. Todo o material que serve para formar o aprendiz tem conteúdo ideológico e tudo o que se diz ilumina e esconde, ao mesmo tempo, a realidade abordada.

A história contada nas cartilhas e livros escolares está cheia de equívocos dessa natureza, com omissões gravíssimas de grandes conflitos sociais que resultaram de movimentos violentos de dominação e de exploração dos mais fracos. A questão agrária no Brasil, um dos problemas cruciais que enfrentamos há séculos, sequer é tocada; falar em latifúndios parece um tabu, quando o próprio Censo Agropecuário denomina média propriedade aquela que tem em torno de 2000 hectares, ou seja, extensões maiores que alguns países da Europa. Identifica-se, a partir da implementação das políticas neoliberais uma concentração de terras ainda maior, com invasões de territórios indígenas, cujos habitantes são massacrados na defesa de suas 
terras7 . A maior concentração ocorreu principalmente no governo FHC: a "área titulada pelas propriedades com mais de 2000 hectares aumentou de 112 para 124 milhões”. Com a implementação do agronegócio, ainda no governo FHC "dois milhões de trabalhadores rurais foram desempregados e 960 mil sítios com área inferior a 100 hectares foram extintos" (FRANCO, 2005, p. 33).

Na história do Brasil encontramos muitos "contos da carochinha", como o descobrimento do Brasil, os conflitos de Canudos e do contestado, Tiradentes, etc. O contestado, por exemplo, teve como pano de fundo a disputa de terras por empresas estrangeiras que aqui aportaram para construir uma ferrovia com o objetivo de extrair riquezas naturais e colonizar o Sul do Brasil. As populações ali residentes resistiram em defesa de suas pequenas propriedades e, como o movimento nasceu espontaneamente, foi envolvido por ideologias religiosas, que acabaram prevalecendo na imagem histórica que se fez desses camponeses, como místicos amalucados. Essa imagem prevaleceu, escondendo os reais interesses econômicos e imperialistas que, no curso de cem anos, transformaram uma grande floresta de araucárias em grandes extensões de plantio de pinus, com uma população de camponeses extremamente empobrecida.

Como acentua Saviani (2003, p. 75), pedagogia “significa não apenas a condução da criança, mas a introdução da criança na cultura”. Apresentar meias verdades como se fossem verdades universais é o que existe de mais desonesto com a criança e o adolescente, uma violência dissimulada que os torna indivíduos despolitizados e incapazes de decidir autonomamente sobre questões sociais e políticas, pelas quais indiretamente são responsabilizados. O resultado é bem conhecido na atualidade brasileira, com um congresso pleno de religiosos defendendo políticas arbitrárias, com indivíduos manifestando-se pelo retorno da ditadura militar e, ao mesmo tempo, defendendo a paz e outras atitudes contraditórias entre si que, se tivessem tido boas aulas de história na escola, certamente não estariam tomando. Esta situação demonstra, antes de tudo, o estrondoso fracasso da educação escolar no Brasil.

\footnotetext{
7 A implementação do neoliberalismo a partir da década de 1990 ampliou as condições de concentração fundiária no Brasil: conforme Pires (2012, p. 21-2), os próprios dados do IBGE confirmam a disparidade na distribuição da terra: as pequenas propriedades "com menos de 10 hectares - representam $47 \%$ do contingente de estabelecimentos agrícolas no país, enquanto a área ocupada por eles é de apenas 2,7\% do total"; as propriedades "com menos de 100 hectares são cerca de $90 \%$ do total, ocupando uma área em torno de $20 \%$ \%; as propriedades "com área maior ou igual a cem hectares representam apenas 9,6\% do total", mas ocupam "78,6\% da área dedicada a atividade" com "mais de mil hectares" correspondem a "0,9\% do total, mas ocupam 43 \%" da área cultivável.
} 
A escola é um espaço de aprendizagem importante para as classes trabalhadoras porque permite o acesso aos códigos de raciocínio e de elaboração do saber; sem esses instrumentos torna-se muito difícil sair do imediatamente dado na prática cotidiana ou, como acentua Gramsci, superar no âmbito da política os limites do econômico corporativo ou a fase inicial de espontaneidade das explosões insurrecionais.

Cabe acentuar que a superação da barreira entre intelectuais e classes populares tem que passar necessariamente pela educação e pela escola, o que se depreende das palavras:

O elemento popular 'sente', mas não compreende nem sabe; o elemento intelectual 'sabe', mas não compreende e principalmente não sente. Os dois extremos são, portanto, o pedantismo e o filisteismo de um lado, a paixão cega e o sectarismo do outro. [...]. O erro dos intelectuais consiste em crer que se possa saber sem compreender e especialmente sem sentir e estar apaixonado, ou seja, que o intelectual possa sê-lo apenas se distinto e destacado do povo (Q. 4, p. 451-2).

Sentir e compreender como o povo implica unir-se a ele, fazendo o trabalho de explicação de uma situação histórica determinada, "vinculando-o dialeticamente às leis da história, a uma concepção de mundo superior e cientificamente elaborada, o 'saber'[...]” (Q. 4, p. 452). O lugar privilegiado para essa relação é a escola e o que motiva o professor a continuar com todas as limitações que lhe são impostas pelos governos e suas políticas públicas é, precisamente, orientar o aluno e acompanhar o seu florescimento intelectual. Os olhos se iluminam quando o aluno supera os limites do positivismo e consegue perceber a realidade de modo dialético. Ensinar implica mostrar as perspectivas discordantes da realidade, desvelar sinais da grandeza do passado e seus significados em novo contexto histórico, iniciar o aluno na dimensão simbólica e política, que se concretiza num pensamento organizado.

Gramsci compara o professor ao místico, que sabe, compreende e sente, como escreve no artigo A luz que se apagou: "pensem naquilo que na Idade Media, representa o movimento franciscano diante do teologismo doutrinário da Escolástica”. O "intelecto havia matado o sentimento, a reflexão cuidadosa tinha estrangulado o ímpeto da fé". E veio "São Francisco, alma humilde, descuidada, espírito simples", que renovou a teologia e "fez renascer em cada alma a divina embriaguez”. Assim também é o professor, aquele toma pelo braço e guia; com ele a "palavra não é mais elemento

8 Tradução publicada no livro Antologia filosófica, da Secretaria da Educação do Paraná. 
gramátical a dividir em regras", mas um som, uma nota musical, poesia que "estimula nossa capacidade criativa", desperta ecos distantes do passado, revigorando o presente (GRAMSCI, 1975, p. 10-12).

A questão colocada evidencia que toda educação é ideológica, na medida em que forma o modo de pensar e de sentir. No processo de aprendizagem a direção do professor é importante, na medida em que mostra possibilidades de leitura autônoma. A ideologia permeia este trabalho e tudo o que acontece no ambiente escolar, basta ler com atenção as cartinhas e todo o material didático, a organização dos currículos, os planos de aula. Cabe utilizar desses instrumentos da melhor maneira para que as classes populares consigam, por meio desses instrumentos, acessar ao conhecimento para a sua emancipação política. 